\title{
MIGRACIONES CAMPO-CIUDAD EN EL MAGREB
}

\author{
Gloria Inés Ospina ${ }^{1}$ \\ UNISCI
}

\begin{abstract}
El movimiento de población del campo a la ciudad ha sido considerado uno de los factores que inducen desequilibrios regionales en todos los países donde se ha producido. El mundo cada vez es más urbano y ello conlleva que las actividades de la ciudad atraigan a gran número de población, que indefectiblemente proceden de las zonas rurales. En el caso que nos ocupa, el fenómeno de éxodo rural se ha visto como un desafío para todas las reformas que los países del Magreb central, Marruecos, Argelia y Túnez, han ido realizando a lo largo de su corta vida independiente. El artículo expone los resultados poco esperanzadores que se han obtenido con las reformas que se han ido introduciendo, pues los flujos de migración campo-ciudad continúan y continuarán.
\end{abstract}

Resumen:

Palabras clave: Flujos migratorios campo-ciudad, políticas agrícolas, Magreb, Marruecos, Argelia, Túnez.

Title in English: "Rural-Urban Migration in the Maghreb"

\begin{abstract}
:
Internal migration flows from rural to urban areas have been considered one of the leading factors in the creation of regional imbalances where they occurred. The world is becoming more urban, and this implies that the activities of the city attract many people, which inevitably come from rural areas. In the present case, the phenomenon of rural exodus has been considered as a challenge to all the agricultural reforms implemented by the Maghreb countries in their short period of life since independence. The article explains the results obtained with the reforms and stress that rural-urban migration flows continue and will continue in the next coming years.
\end{abstract}

Keywords: Rural-urban migration, Agricultural policies, Maghreb, Morocco, Algeria, Tunisia.

\section{Copyright $@$ UNISCI, 2013.}

Las opiniones expresadas en estos artículos son propias de sus autores, y no reflejan necesariamente la opinión de UNISCI. The views expressed in these articles are those of the authors, and do not necessarily reflect the views of UNISCI.

\footnotetext{
${ }^{1}$ Gloria Inés Ospina Sánchez es Historiadora y Geógrafa de la Población, Investigadora UNISCI, Sección Inmigración y Miembro del Foro Hispano-Argelino.

Dirección: Facultad de CC. Políticas. Dpto. de Relaciones Internacionales. Universidad Complutense de Madrid. Campus de Somosaguas. 28223 Madrid, España.

E-mail: ginesos@hotmail.com.

http://dx.doi.org/10.5209/rev_UNIS.2013.n31.44700
} 


\section{Introducción}

Los estudios que se han realizado hasta la actualidad sobre migraciones campo-ciudad en los tres países del Magreb aquí señalados, como son Marruecos, Argelia y Túnez, tienen la validez de estar elaborados por expertos de cada uno de los países, conocedores de sus problemas y de sus aciertos en la materia y que se han movido por el terreno. Con lo cual, queremos indicar que nuestras fuentes son, en cierta medida, válidas, no descartando poder investigar in situ, tomando como modelo una zona concreta en cada uno de los países mencionados, para conocer, mediante la investigación de campo, el comportamiento de los parámetros aquí tenidos en cuenta, como son los elementos de expulsión de la población de su tierra, y los elementos de atracción que les mueven a salir de ella hacia las ciudades.

Es un hecho constatable, por medio de todos los estudios consultados, que la evolución y el cambio social que han experimentado estos países del Magreb, les están conduciendo hacia un progresivo urbanismo, que ya se experimentó en los años 60 en España.

Quiero lanzar la hipótesis, de que los gobiernos de estos países del norte de África, habrán de poner todos los medios necesarios para evitar que la población campesina abandone sus lugares de origen, evitando con ello la degradación del campo y la sobrepoblación de las ciudades, contribuyendo a prevenir la inseguridad alimentaria de sus países.

Desde el pasado, Marruecos, Argelia y Túnez, se han caracterizado por tener una serie de denominadores comunes en su historia, que les distinguen claramente, respecto a los países vecinos. Por una parte, antes de la colonización occidental, el Magreb central, se distinguió por su carácter mayoritariamente rural y la organización social se basada en una estructura tribal, estructura que fue considerada durante mucho tiempo como rígida y fija, pero que en realidad, tuvo capacidad de adaptación a acontecimientos históricos variables, así como a unas condiciones medioambientales muy severas. Los tres países también fueron colonizados por Francia, (caso especial Marruecos, como Protectorado español, por un tiempo), y los tres han experimentado movimientos migratorios interiores muy fuertes desde los años de la independencia hasta la actualidad.

Sin dejar de apuntar los prolegómenos de los movimientos internos que se han ido sucediendo a lo largo de su corta historia independiente, las migraciones del campo a la ciudad, a partir de los años ochenta, se desarrollan de una forma particular, porque además de incrementar los efectivos en las ciudades, "empujan" a gran número de personas hacia el exterior del país.

Hay autores que llegan a afirmar que las migraciones internacionales desde los países del Magreb hacia la Unión Europea, Canadá y los Estados Unidos, son un "camuflaje" de las auténticas migraciones que se producen dentro de los tres países, que son movimientos internos de la población campesina hacia las ciudades y "antesala" de las migraciones exteriores, una vez se han conseguido los mínimos objetivos que llevaron al campesino a la ciudad, y ante la imposibilidad de mejorar su nivel de vida, como lo había previsto.

Por otra parte, se señala que en los tres países hay denominadores comunes en cuanto a la generación de empleo en el campo, caracterizada por la baja ocupación debido a la escasa renta rural y a los inconvenientes que el campo ofrece a los campesinos, especialmente en cuanto a educación y servicios básicos como contar con red eléctrica o servicios sanitarios y 
educativos de cierta calidad, y la conveniente comercialización de sus productos, entre otras cuestiones.

Otro factor a añadir es el rápido crecimiento que ha experimentado la población urbana, gracias a los flujos de migración rural, que se han ido intensificando a partir de los años ochenta, entre otros muchos factores. (Véase al respecto los estudios de Raquel Barras y de Gracia Abad, en este misma revista)

En todos influye de forma determinante la estructura agraria, dual, y el clima, así como la zona de cultivo que varía según se trate de Marruecos, que cuenta con una superficie de $44.630 \mathrm{Km}$ cuadrados, de los que sólo el $19 \%$ es de tierras arables, el resto lo ocupa el desierto del Sahara; Argelia, país extenso, dominado por el desierto, y de los 238 millones de has con que cuenta, sólo nueve millones forman la superficie agraria útil; y Túnez, que ocupa una superficie de $165.000 \mathrm{~km}$ cuadrados, de los que el $20 \%$ forman la superficie agraria útil, el resto del territorio lo constituye el desierto del Sahara.

En datos de Naciones Unidas-Habitat de 2008, la población rural mundial continuó sobrepasando a la población urbana mundial hasta el año 2007. Los tres países del Magreb que aquí tratamos, en este año 2007contaban con un $42 \%$ de población rural y entre un 20 y un $25 \%$ de pobres. De estos últimos, el $70 \%$ vivía en el medio rural.

Según este mismo informe, la concentración de pobres en el medio rural es el resultado de las políticas gubernamentales de los países en vías de desarrollo, que tienden a favorecer a la población urbana en detrimento de la población rural.

\section{Marruecos}

\subsection{Población}

La población marroquí cuenta con 32 millones de habitantes, de los cuales un 60\% pertenecen a las áreas urbanas, representadas por Casablanca, Rabat-Salé, Fez, Oujda SoussMassa-Draa, Marrakech-Tansift-Alhaouz, y el 40\% restante a las zonas rurales.

Por millones de habitantes, desde el año 1960 hasta la actualidad, la población rural ha experimentado una variación en sus efectivos, hacia la disminución de los mismos, respecto a la población urbana, de forma notable a partir del año 1994, como se puede ver en la siguiente serie: 
Tabla 1. Variación de la población rural

$\begin{array}{lccc}\text { Población/año } & \text { Urbana } & \text { Rural } & \text { Total } \\ 1960 & 3.411 & 8.215 & 11.626 \\ 1971 & 5.268 & 9.935 & 15.303 \\ 1982 & 8.730 & 11.689 & 20.419 \\ 1985 & 13.940 & 14.541 & 28.481 \\ 1994 & 13.407 & 12.665 & 28.705 \\ 2004 & 16.464 & 13.428 & 29.891 \\ 2007 & 17.258 & 13.752 & 31.010 \\ 2011 & 18.408 & 13.864 & 32.272\end{array}$

Con una diferencia de casi dos millones de personas, en el medio rural se aprecia un repunte en 2004, seguramente debido al crecimiento vegetativo de su propia población, que se mantiene a niveles sostenidos.

El año 2004 presenta unos índices demográficos, que indican que más de la mitad de la población total marroquí vive en el medio urbano, que se sigue incrementando en los años 2007 y 2011, mientras que los efectivos que pertenecen al medio rural se mantienen en cifras parecidas al año 2004. Concluyen que este país se encuentra en la vía del cambio social progresivo, teniendo en cuenta que el medio rural va siendo despojado de costumbres ancestrales, como es el paso de una familia tradicional o familia extensa, a la familia nuclear o reducida, que progresivamente se va configurando en el medio urbano marroquí. (Véase el capítulo de Gracia Abad sobre Población y el de Raquel Barras sobre Urbanismo, en este mismo estudio).

\subsection{Migraciones del campo a la ciudad}

Hay estudiosos de las migraciones que indican que para comprender las migraciones campociudad es imprescindible señalar los factores que llevan a los campesinos a tomar una decisión costosa para ellos y sus familias, factores entre los que se incluye la precariedad de sus modos de vida tradicional, el cercamiento de las tierras comunales y en definitiva, la destrucción de sus medios para sustentarse. Algo muy parecido a lo que ocurrió en la Inglaterra del siglo XVIII, cuando el campesinado fue arrojado fuera de las tierras comunales y se vio obligado a emigrar a las zonas urbanas en busca de empleo en la naciente industria inglesa. Son los llamados factores de expulsión. Por tanto, Marruecos como todas las sociedades en vías de desarrollo, presenta numerosos desequilibrios internos, que son el motor de expulsión de un número notable de población marginal, o a punto de serlo, hacia áreas de 
suficientes recursos, pero que tampoco cuentan con la suficiente infraestructura urbana, como para impedir también la marginación y la pobreza alrededor y en el interior de las ciudades.

Como en Argelia y Túnez, Marruecos experimentó numerosos trastornos con la colonización francesa, debido a los desequilibrios provocados en el medio rural con respecto a la incipiente urbanización, con la que conservaba un cierto equilibrio. Las migraciones internas en esta época consistían fundamentalmente en contingentes campesinos que servían en el ejército o en las plantaciones coloniales.

Una vez conseguida la independencia, y habiéndose replegado, franceses y españoles a sus metrópolis, se produjo el primer gran movimiento de población del campo a las ciudades, como símbolo de conquista de sus tierras y también buscando seguridad en el medio urbano.

No obstante, el reino Alauita conservó la estructura de producción agrícola colonial, que se llevó a cabo entre los años 1912 y 1956. En este período el sector agrícola se integró en la economía global a través de la transformación de extensas zonas de secano, convertidas en zonas de regadío para la producción de verduras de huerta y cítricos. También se debe a la herencia francesa el sistema de relaciones "clientelares", jerarquizadas, que subsisten hoy en día, para la asignación de títulos de propiedad sobre los campos de cultivo y la toma de decisiones en lo que a la planificación de la actividad agrícola se refiere.

Entre los años 1961 y 1991, durante el reinado de Hassan II, el gobierno marroquí, ya independiente, consolidó las reformas iniciadas durante la administración francesa utilizando las mejores tierras de cultivo para la producción de cultivos de exportación como los cítricos, tomates y cereales. Cultivos intensivos y extensivos, que eran propiedad de empresas agrarias, cuyo administrador era el Estado marroquí.

Para continuar con la expansión del regadío, Marruecos solicitó préstamos al Banco Mundial en el año 1964. Como consecuencia, el sector tradicional de secano quedó estancado, al mismo tiempo que el país experimentaba el aumento de su población, lo que obligó al gobierno marroquí a importar cereales desde el exterior. Dicen los expertos que, hasta el momento Marruecos era un país autosuficiente y a partir de entonces tendrá un importante déficit en su balanza de pagos, gracias a las importaciones de productos destinados a la alimentación.

Antes de adentrarnos en la situación que marcará las migraciones más importantes a partir de los años ochenta y los ajustes estructurales en el sector agrario de este país, veamos qué circunstancias y factores nos permitirán dilucidar si este país y su gobierno tendrá la perspectiva de futuro para prevenir la carestía alimentaria y asegurar un nivel mínimo de abastecimiento de alimentos básicos a su población.

\subsection{Población agraria}

Como lo hemos advertido en el cuadro $\mathrm{n}^{\mathrm{a}} 1$, la población rural aún representa una parte considerable del conjunto de la población marroquí. Concretamente de los 32.272.000 habitantes que tenía Marruecos en 2011, 13.864 .000 vivían en el medio rural. La población que trabajaba en el sector agrario fue en ese año de $43 \%$ de la población total, y dio empleo a un $80 \%$ de la población rural, contribuyendo al incremento del PIB con un 13 y el 20\% dependiendo de la cosecha. 
Por tanto, el sector agrario en Marruecos desempeña un papel muy importante en la economía del país, que se refleja en su impacto en el empleo, en la contribución al PIB y en la participación de las exportaciones al extranjero, que pueden llegar a alcanzar del 15 al $21 \%{ }^{2}$

\subsection{Factores determinantes del sector agrario}

\subsubsection{El clima}

Marruecos se encuentra en la parte sur del Mediterráneo, por tanto su clima presenta las características propias de este zona, a ello hay que sumar un régimen de lluvias que presenta importantes fluctuaciones a lo largo del año, con largos períodos de sequía y con una pluviometría muy escasa, limitada a las zonas costeras. Por esta causa, la actividad agraria se desarrolla con dificultad debido a que el 60\% de la Superficie Agraria Util (SAU) recibe menos de $400 \mathrm{~mm}$ de lluvia al año de media.

Esto explica la importancia del regadío y que el gobierno marroquí lo haya convertido desde hace años en el centro de la política agraria. A pesar de ello, en los años 1980 y 1981, cuando el país sufrió los efectos de una larga sequía, no sólo se produjo un movimiento de población del campo a la ciudad, sino también se puso de relieve, que a pesar de las reformas emprendidas en el sector agrario para intensificar las superficies de regadío, éste seguía siendo demasiado frágil, debido al escaso desarrollo de infraestructuras hidráulicas. (Véase al respecto, los estudios del equipo de Ingenieros Agrónomos, en este mismo estudio)

Por cierto, como lo afirman diferentes especialistas en ciencias sociales, este movimiento de población no sólo se dirigió a las ciudades marroquíes, sino que produjo un "empuje de población" hacia el exterior, especialmente hacia Francia, España e Italia.

\subsubsection{Estructura de la propiedad}

Marruecos, mantiene una estructura agraria arcaica, caracterizada por la dualidad. El $75 \%$ de las explotaciones no pasan de 4 has, con una mínima mecanización y con una producción dedicada al autoabastecimiento rural. De estas explotaciones hay aproximadamente un 25\% que tienen dimensiones inferiores a una hectárea y se encuentran inmersas en la marginalidad económica al ser imposible el desarrollo de la actividad agraria en condiciones de viabilidad. El 25\% restante, se compone de grandes explotaciones agrícolas, que producen la mayor parte de los productos del país y también los de exportación. Las cifras de producción que se evaluaron para este $25 \%$ de explotaciones, en el año 2010, fue de $80 \%$ de los cítricos del país, principal producto agrícola para la exportación junto con el tomate, el 35\% de hortalizas y un $15 \%$ de cereales. A todo ello se une la escasa mecanización y por consiguiente el nivel bajo de rentas que se puedan obtener en este sector rural-agrario. (Véase al respecto el trabajo de Antonio Alonso en este mismo estudio).

\footnotetext{
${ }^{2}$ Faces. F.: "Marruecos: La larga marcha hacia la modernidad y el desarrollo sostenible", Instituto Internacional San Telmo (2010), en http://www.extenda.es/web/export/sites/extenda/archivos/redexterior/encuentro_marruecos/ponencias_dia5/ASEIN-11_Marruecos_2010_ACTUALIZADO.pdf.
} 


\section{Cambio de ritmo económico}

A principios de los años ochenta, la economía marroquí se encontraba con una situación financiera muy complicada, debido al elevado endeudamiento exterior. Dificultades financieras que se debían a factores exógenos como la fuerte caída de los ingresos por exportación de fosfatos, y a causas internas, como el excesivo coste de un sector público sobredimensionado, así como la dependencia de la producción agrícola del clima, con una permanente sequía durante estos años.

A partir del año 1983, Marruecos inicia un nuevo camino para salir de esta crisis. Solicita asesoramiento del Banco Mundial y del Fondo Monetario Internacional, que le proponen un Plan de Ajuste Estructural, con el objetivo de animar la inversión extranjera, promover las exportaciones, abolir los aranceles, $\mathrm{y}$, en definitiva, limitar el endeudamiento. En contrapartida los nueve Planes de Ajuste Estructural que Marruecos aceptó le hicieron cada vez más dependiente del FMI. Planes que se basaban en la liberalización de la economía nacional y su apertura sobre los mercados exteriores. En 1987, Marruecos se adhiere al GATT.

\subsection{Consecuencia de los Planes de Ajuste Estructural (PAEs)}

Como consecuencia de los PAEs, las tierras de pastoreo han ido desapareciendo, por la privatización y el cierre de las mismas, para engrosar en la propiedad de las haciendas de gran tamaño, que son controladas por una minoría, mientras que los campesinos y pastores van siendo desposeídos de sus medios de vida. Cuestión que se veía venir, a partir de la elaboración del "Code de Investissements Agricoles", realizada por técnicos del Banco Mundial, que aconsejaban al gobierno de Hassan II, convertir estas tierras a la agricultura de irrigación, para mejorar la productividad agrícola, luchar contra la fragmentación de las explotaciones y repartir títulos de propiedad. Al mismo tiempo que se evitaba la degradación ambiental se modernizaría la agricultura del país.

Para los campesinos de las zonas rurales de Marruecos, la falta de acceso a las tierras de uso colectivo significó la pérdida de una fuente imprescindible de medios de vida y sustento, lo que agudizó la pobreza rural y empujó a los campesinos a emigrar a las zonas urbanas, en busca de un empleo, especialmente en Casablanca, Tánger y Rabat.

Como consecuencia, la pobreza urbana aumentó, ya que la mayor parte de los pobres urbanos fueron aquellos que recientemente se vieron obligados a emigrar del medio rural, porque el campo ya no les pudo alimentar. Con el agravante, de que en los suburbios de las ciudades, la mayor parte de estos campesinos pasan a formar parte de la mano de obra clandestina, de la economía "informal” y abocados a la marginalidad.

Las familias campesinas que conservaron acceso a un pedazo de tierra colectiva o que pudieron contar con modestos medios para producir y comercializar alimentos, intentan sobrevivir en el campo, a costa de tener que enviar a sus miembros más jóvenes a trabajar en fabricas de las ciudades industriales, completando de este modo sus ingresos. Ingresos familiares que se redondearon a costa de un trabajo de "explotación", sufriendo la jornada laboral de hasta 12 horas, sin contrato de trabajo y con sueldos mínimos, que en muchos casos no llegan a los 200 euros al mes, sueldo del que deben enviar una parte a sus familias en el campo. (Consúltese al respecto los trabajos de Raquel Barras y de Gracia Abad en esta misma revista). 
Hay investigadores que consideran que el trabajo fabril que encuentran los campesinos en las ciudades representa un factor positivo, porque ayuda a la economía familiar, sin embargo, habría que evaluar en qué circunstancias se desarrolla ese trabajo en las fábricas de las ciudades marroquíes y a qué precio para la vida y la dignidad de las personas.

Otro de los colectivos que también ha sufrido con las reformas promovidas por el gobierno marroquí, han sido los pueblos nómadas y ganaderos, mientras que los beneficiarios de la reestructuración ha sido la familia real y la élite situada a su alredor. En concreto, el holding empresarial Omnium Nord Africain (ONA), ha ido comprando la mayoría de las empresas privatizadas. Igualmente es la familia real quien recibe directamente los beneficios de la Office Cherifien des Phosphates, o monopolio estatal del comercio de fosfatos.

\section{Flujo migratorio en cifras}

Según el Centro de Estudios e Investigaciones Demográficas, (CERED), el flujo migratorio de las zonas rurales a los centros urbanos se estimó en una media anual de 155.000 personas, en el período entre los censos de 1982 y 1994. Esta media alcanzó las 200.000 personas en la década de los noventa. Se afirma que el $47 \%$ de la población urbana tuvo su origen en el éxodo rural entre 1994 y 1998.

Según la media anual calculada por el CERED, en el período 1900 a 2004, el éxodo rural presentó el siguiente saldo migratorio:

De 1900 a 1912, hubo un saldo migratorio de 7.800 personas desplazadas del campo a la ciudad.

De 1912 a 1926 , fue de 11.400

De 1926 a 1936, fue de 17.300

De 1936 a 1952, fue de 29.000

De 1952 a 1960 , fue de 45.000

De 1960 a 1971, fue de 67.000

De 1971 a 1982, fue de 113.000

De 1982 a 1994, fue de 193.000

De 1994 a 2004, fue de $106.000{ }^{3}$

\section{Continúa la liberalización}

Con el progresivo avance en la liberalización de aranceles desde 1993 (del 65\% al 22\%), la zona marroquí se ha convertido en un mercado atractivo para la UE. Así, en 1995 se firma el Acuerdo de Asociación UE- Marruecos, que entró en vigor a partir del año 2000. Acuerdo que

\footnotetext{
3 (Estimación provisional del "Centre des Recherches et des Études Démographiques" CERED: en “Demographie Marrocaine: 50 Ans de Développement Humain. Perspectives 2025” (2006), p. 46.
} 
ha permitido la creación de la Zona de Libre Comercio (ZLC) entre la UE y Marruecos, con el objetivo de reducir progresivamente las barreras arancelarias hasta alcanzar un 5,2\% en 2012.

No obstante, Marruecos ha sido considerado un "vecino preferente" en las transacciones comerciales con la UE desde 1976, pues sus productos han tenido entrada libre al mercado comunitario y también la UE, ha permitido la exportación del $20 \%$ de sus productos agrícolas con un tratamiento preferencial.

Con los acuerdos preferenciales con la UE, desde 2004 hasta el de 2012, Marruecos busca incorporarse a un grado de vecindad que le puede favorecer a corto plazo, con el Plan Marruecos Verde, pero que a largo plazo puede verse abocada a que su producción quede en manos extranjeras y que su población tenga que seguir emigrando hacia el exterior.

No obstante, la serie de planes para reducir la pobreza en Marruecos debe seguir y vigilar que sean viables, evitando la corrupción e impidiendo que sea para el beneficio de unos pocos.

En septiembre de 2012 se da vía libre al desarme arancelario entre Marruecos y la Unión Europea, por medio de la aprobación del Acuerdo Agrícola, que permitirá la entrada libre a la U.E. de productos producidos en Marruecos, como el tomate, pimiento, melón, que afectarán y pondrán en peligro a más de 65.000 puestos de trabajo, sólo en la región de Murcia. ${ }^{4}$ Por su parte, en las islas Canarias, la Asociación de Agricultores y Ganaderos (ASAGA) calificó el acuerdo como de "auténtico batacazo", porque coloca a las islas en una situación de indefensión y vulnerabilidad. ${ }^{5}$

Los problemas estructurales del mercado agrícola liberalizado son los mismos para los agricultores de Marruecos que para los de la U.E. Por ello es importante que los mercados estén regulados, se protejan las producciones locales y se creen mecanismos para proteger las ganancias de los agricultores, y no sean solamente los intermediarios y exportadores los que tengan pingües ganancias. (Véase el artículo de Antonio Marquina, en este mismo estudio)

\section{Argelia}

A 1 de enero de 2012, La población argelina era de 37.100.000 de habitantes ${ }^{6}$ y se prevé que de mantenerse el ritmo de crecimiento de 2011, Argelia alcanzará los 37.800.000 de habitantes, el 1 de enero de 2013.

En la actualidad, todavía el 55\% de la población argelina vive en el medio rural. De estos, el $70 \%$ tiene menos de 30 años. Cuando el trabajo escasea, los campesinos más jóvenes emigran a la ciudad.

Argelia ha experimentado una urbanización extremadamente rápida, al mismo tiempo que un éxodo rural intenso, que ha contribuido a aumentar el número de habitantes en las ciudades. Lo que, para investigadores en migraciones, viene a señalar la importancia de las

\footnotetext{
4 "Indignación por el acuerdo con Marruecos", La Verdad, 16 de febrero 2012, en http://www.laverdad.es/murcia/20120216/local/region/eurocamara-verde-acuerdo-agricola-201202161243.html.

5 "Asaga: El acuerdo agrícola con Marruecos es "auténtico batacazo",

Universo Canario, 17 febrero 2012, en http://www.universocanario.com/economia/canarias/asaga/acuerdoagricola-con-marruecos/293940.

"Según datos de "L’office nacional des estatistiques (ONS)" (2011).
} 
relaciones entre el campo y la ciudad, de tal forma que estas pueden ser complementarias o convertirse en hostiles, pero sea como fuere, de aquí en adelante, las relaciones entre el campo y la ciudad serán siempre indisociables.

Para los expertos en temas migratorios argelinos, Argelia es un ejemplo particularmente interesante, en este sentido, por la especificidad de su historia, los trastornos provocados por la colonización y la política de autogestión que el Estado implantó después de la independencia, así como las respuestas efectivas de su población.

\subsection{Movimientos internos de la población argelina}

Una vez llegado a la independencia, Argelia sufrió varios movimientos de población del campo a la ciudad, hasta bien entrados los años ochenta. Como consecuencia, se produjo una progresiva masificación de las ciudades, como Orán, Annaba y Constantina, al asentarse en sus alrededores poblaciones procedentes del campo, en busca de seguridad, salarios dignos, trabajo y educación, formando cinturones de habitat "ilegal", produciendo un progresivo desequilibrio social, que fue corregido, en un principio, con "dureza", por las autoridades, y que después ha ido conviviendo con otras prácticas urbanísticas. ${ }^{7}$

De hecho, la población rural argelina ha padecido una constante disminución a lo largo de su corta historia independiente en contra del progresivo aumento de la población urbana. Lo que viene a confirmar, que el aumento de la urbanización se produce a costa de los flujos migratorios rurales. Tal como lo hemos descrito en Marruecos.

En el año1966, la población rural argelina representaba el 68\% del total de la población, en el año 1977, disminuyó hasta el 60\%, para en 1987, representar ya el 50,3\%, en el año 2004 llegó a disminuir hasta representar sólo el 39, 2\% de la población total argelina, y en 2005 pasaría a tener un peso de sólo el 37\% de la población total argelina que era de 32.000.000 de habitantes, según datos de la Oficina Oficial de Estadística argelina. En estimaciones de la FAO, esta tendencia tenderá a ralentizarse hasta el año $2010 .^{8}$

Efectivamente, desde la época de la colonización, en Argelia, el movimiento de las poblaciones del campo a la ciudad ha sido una constante. En un principio debido a la desposesión y subproletarización de los fellahs, al instalarse en Argelia el capitalismo colonial desestructurando unas relaciones campo-ciudad que hasta el momento aseguraban una cierta organización social en ambos medios, según lo aseguran los expertos argelinos en migraciones. ${ }^{9}$ Esta irrupción colonial provocó un éxodo rural masivo que llegó a las puertas de las ciudades ${ }^{10}$ y más tarde la guerra arrastró a más de tres millones de campesinos, de los que un tercio terminó refugiándose en las ciudades, otro formó lo que más tarde sería las periferias urbanas y el otro tercio volvió a sus aldeas. La guerra trajo también mayor conmoción dentro de la población argelina autóctona que entre la europea, que se replegó hacia la costa, mientras que los campesinos argelinos inundaban las periferias de Orán, y pasaban a engrosar la masa de parados.

\footnotetext{
${ }^{7}$ Isnard, Hildebert: "Algérie ou décolonisation difficile”, Méditerranée, vol. 10, no 3 (1969), pp.325-340, en http://www.persee.fr/web/revues/home/prescript/article/medit_0025-8296_1969_num_10_3_1325.

${ }^{8}$ Bessaoud, Omar: "La stratégie de développement rural en Algérie. Options Méditerranéennes", Serie A, no 71 (2006), en http://ressources.ciheam.org/om/pdf/a71/06400059.pdf.

9 Entre los estudios más completos y minuciosos, se encuentra el del profesor Bouziane Semmoud, de la Universidad de Artois: "Crisis y sociedad en Argelia. Introducción a una geografía social de las grandes ciudades, Eria (1995), pp. 257-268, en http://www.unioviedo.es/reunido/index.php/RCG/article/view/1207/1126.

${ }^{10}$ Besaoud, op. cit.
} 
Según los datos recabados por los autores ${ }^{11}$ entre 1954 y 1966 las ciudades de Orán, Argel y Constantina recibieron cerca de un millón de personas provenientes del campo, pero fue en Orán y Argel donde la sustitución de población europea por argelina se produjo de forma masiva. Pero fue Orán la que recibió oleadas de campesinos ${ }^{12}$ que se asentaron en el interior y alrededor de la ciudad, que hasta los años setenta, formando asentamientos informales, los denominados "bidonvilles", que provocaron disfunciones, como fue la de ocupación de tierras agrícolas de los alrededores, donde se colocaron las poblaciones rurales desarraigadas y abocadas a la marginalidad en estas ciudades de Orán y Argel, principalmente. $^{13}$

\section{2. Éxodo rural e incremento de las aglomeraciones de todo tamaño}

Como se ha venido enfatizando, el fenómeno del éxodo rural es a la vez origen del surgimiento de cientos de aglomeraciones y del crecimiento y despliegue de los centros urbanos. El éxodo rural que se produjo en España, por ejemplo, en los años sesenta, fue motivado por la creación de polos de desarrollo alrededor de ciudades como Madrid, éxodo en función de los avances industriales y del progreso económico. En el caso de Argelia, el éxodo rural está más ligado a las desventajas y consecuencias de las dificultades asociadas a la vida en el medio rural. ${ }^{14}$

El medio rural se encuentra en una situación de marginalidad creciente, lo que favorece su despoblamiento. En 1966 Argelia no contaba más que con un 30\% de población urbana, mientras que en el año 2008, esta proporción se había incrementado hasta representar el $70 \%$.

A pesar de todos los esfuerzos que se han realizado para mejorar la situación de las zonas rurales, éstos se han quedado en meras reformas muy puntuales, como la construcción de escuelas o centros de salud, o la realización de algunos proyectos para comunicar las zonas y también la canalización y tomas de agua para las poblaciones, que en definitiva no han impedido que los flujos migratorios continuaran hacia las ciudades, en particular hacia Argel.

Entre los factores que han empujado a los habitantes campesinos a emigrar hacia las zonas urbanas están las posibilidades de empleo y las dificultades de comunicación. Los expertos en temas económicos subrayan que las dificultades ligadas al mundo del trabajo son agravadas por el aislamiento de que son víctimas las zonas rurales, al no contar con suficientes comunicaciones, como el ferrocarril, que les unan a los centros urbanos. Y en este sentido Argelia cuenta con ciertas zonas enclavadas en regiones con estas características. Como solución a la hipertrofia de Argel, estaría la mejora de los recursos que permitieran a los trabajadores ir a ganar los salarios a la ciudad, sin tener que ir a vivir a la ciudad.

Hacia 1970, cerca de un 60\% de la población argelina vivía fuera de las ciudades, pero esta circunstancia cambió después, cuando se produjo un éxodo rural muy importante, hacia 1997, que según los estudiosos, ha jugado un papel esencial en el desarrollo de la crisis social, política y económica que sacudió Argelia. Desarticulación de una sociedad tradicional, que

\footnotetext{
${ }^{11}$ Véase al respecto: Chadli, Mohamed; Ziane, Mahfoud y Djellali, Dahmane: "Hypertrophye et exclusión territoriales", Les Cahiers du CÉRIUM, vol. 1, no 1 (Invierno 2012), en http://cahiers.cerium.ca/IMG/pdf/CHADLI_ZIANE_et_DJELLALI__Alger_hypertrophie_pdf.

${ }_{12}^{12}$ Campesinos que procedían de la Kabilia, región pobre que sufrió mucho durante la guerra de independencia.

${ }^{13}$ Un interesante estudio sobre la ocupación de tierras agrícolas alrededor de las ciudades principales en Argelia, es el que han escrito Boudjenouia, Abdelmalek; Fleury, André y Tacherift, Abdelmalek: "L'agriculture périurbaine à Setif (Algérie): quel avenir face à la croissance urbaine?”, Biotechnol. Agron. Environ., vol. 2, nº 1 (2008), pp. 23-30.

${ }^{14}$ Ibid.; Chadli et al., op. cit.
} 
facilitó el surgimiento y la implantación de los movimientos islamistas radicales. La lucha del gobierno contra el terrorismo, trajo como consecuencia que hacia el año 2005, el 60\% de la población argelina residiera en el medio urbano.

La capital, Argel, primer puerto marítimo del país, pasó de tener 1.980.000 habitantes en 1990 a tener 3.059.643 habitantes en 2003, gracias al éxodo rural inducido por la inseguridad en el medio rural.

\subsection{El medio rural}

El medio rural es muy similar a los otros países del Magreb, con estructuras arcaicas y bajos niveles de ingresos.

De los 238 millones de has $(2381.741 \mathrm{~km}$. cuadrados) con que cuenta el territorio argelino, sólo nueve millones, $(21,42 \%)$ forman la superficie agraria útil. En cuanto a las explotaciones, Argelia cuenta con un millón de explotaciones agrarias, predominando las explotaciones de pequeño tamaño, de 4 has de media. Las grandes explotaciones son casi todas de empresas públicas y algunas de particulares, estas son las que lideran la utilización de maquinaria agrícola.

Una de las cuestiones más importantes en la actuación del gobierno sobre el sector agrícola es la lucha contra la desertización. El desierto del Sahara que tiene una extensión de unos 2 millones de $\mathrm{Km}$ cuadrados, cubre el 80\% de la superficie de Argelia.

Desde la independencia de Francia, el gobierno argelino se impuso como obligación reconvertir el sector agrícola heredado de la colonización francesa. Aunque ha sido muy difícil su realización debido a que desde un principio se reguló por el régimen de autogestión.

La autogestión se consideró un progreso social en relación al sistema colonial. Para muchos autores argelinos, la autogestión devolvió al campesino (fellah) la dignidad de "Ser Humano", el gusto por la responsabilidad y la iniciativa, sin embargo, y por desgracia, también la autogestión engendró un campesinado privilegiado, "socialmente privilegiado", por los derechos que le fueron reconocidos por la administración de las explotaciones y por la promoción profesional. Económicamente privilegiado en la remuneración de su trabajo y en los beneficios que le fueron consentidos. Privilegiados frente al campesino tradicional hasta que éste se vio obligado a abandonar su economía de autoconsumo.

\subsection{Reformas agrarias}

De los países del Magreb, es Argelia donde más estudios sobre estrategias para el desarrollo del sector agrario se han realizado. No hay precedentes en este tema, en opinión del profesor Omar Bessaoud ${ }^{15}$. Sin embargo, con la explotación e ingresos sobresalientes en los hidrocarburos, las políticas llevadas a cabo por los gobiernos argelinos a favor del sector agrario ha dado unos resultados muy exiguos, tanto que, hay estudiosos de las migraciones internas argelinas que llegan a afirmar que el sector rural se halla en crisis desde la independencia del país.

La primera "revolución agraria" a favor del campo desde la independencia apuntó oficialmente hacia un reparto "justo y eficaz" de los medios de producción agrícola, a través de la redistribución de tierras, que permitió recuperar, de 1972 a 1976, un poco más de un

\footnotetext{
${ }^{15}$ Investigador de la Universidad de Montpellier.
} 
millón de has de calidad desigual, y asignarlas a unos 85.000 campesinos, que representaban un $10 \%$ de pobres rurales sin tierra, reagrupados en cooperativas de producción.

Sin embargo, el principal objetivo de esta operación, según los expertos, fue la lucha contra el éxodo rural. La revolución agraria debía retener el máximo de población en el campo, no sólo por la redistribución de tierras y para relanzar la agricultura, sino también para llevar a cabo una acción de envergadura en materia de hábitat rural. El programa denominado "mil villas socialistas", llevado a cabo desde el verano de 1972, ofreció a los beneficiarios, centros rurales enteramente nuevos, constituidos por 100 o 150 pabellones dotados de electricidad y de agua corriente y provistos de los principales equipamientos colectivos, como escuelas, centros de salud, comercios, etc. Con ello se consiguió un cierto equilibrio y la reducción de las desigualdades entre campo y ciudad. Pero este tipo de hábitat también contribuyó a crear un modelo de consumo urbano y la búsqueda de ganancias extra agrícolas en las regiones más industrializadas. Así las villas socialistas tendieron a convertirse en ciudades de obreros. Sin embargo, el reagrupamiento de familias rurales, antes aisladas, no entró en el cuidado de los nuevos programas socialistas. En total se construyeron 400 villas en lugar de las 1.000 que estaban programadas.

En materia de desarrollo agrícola, los resultados fueron menos brillantes. El sector de producción, muy minoritario, puesto en marcha por las cooperativas comunales, ofreciendo servicios "polivalentes" (CAPCS), tiene un impacto muy desigual. Las prestaciones de trabajos mecanizados con tarifas moderadas, responden a necesidades inmediatas, pero contribuyen a romper la unión entre los pequeños campesinos y su tierra y a limitar su autonomía, reduciendo el papel de los consumidores de servicios. El resultado es una desintegración lenta, pero general de la agricultura familiar, lo que va a producir "la esclerosis" del sector. El estancamiento de la producción agrícola se une al crecimiento demográfico, que agrava constantemente la dependencia alimentaria del país.

Con esta política de autogestión, que según los investigadores consultados, fue impuesta a los campesinos argelinos por las clases que rodeaban al poder, tuvo unos resultados muy pobres, porque no estimulaban la iniciativa creadora del campesinado, y le condenaba a ser un mero ejecutor pasivo, insensible a las virtudes de la estructura colectiva, que sólo tenían el objetivo de asegurar el trabajo asalariado, como única forma de promoción social.

La insuficiencia de la estrategia de desarrollo agrícola va a estar atenuada por algún tiempo, por la capacidad del país para importar masivamente productos alimenticios, gracias a los ingresos del petróleo $\mathrm{y}$, sobre todo, por los efectos positivos de la política de industrialización.

Como consecuencia, se multiplican las actividades y los salarios extra-agrícolas, llegándose a contabilizar hasta 1.644.700, personas como oficialmente ocupadas, mientras que en la agricultura, sólo se contabilizaban $692.000 .{ }^{16}$

En la década de 1970-1980, alrededor de 1.500.000 campesinos emigraron hacia las zonas urbanas, sin que esto tuviera como consecuencias el despoblamiento del campo, porque la población rural continuó incrementándose.

En los años ochenta se experimenta una profunda crisis social y económica, en cuya base se encuentra la regresión y la reorientación de la producción por parte del gobierno

16 Según datos del "Recenscement général de la population et de l’habitat (RGPH)", (1977), en http://www.persee.fr/web/revues/home/prescript/article/medit_0025-8296_1983 num 50_4 2165. 
argelino. A partir de 1982 se inicia lo que muchos autores denominan "el desmantelamiento del aparato productivo argelino", reestructuraciones en los sectores industrial y agrícola, que llevarían a una liberalización, debilitando al sector público y liberando parcelas de actividad especulativa a la iniciativa privada que se encontraba con problemas de inversión y con ambición de expandirse. Esta iniciativa va a tener consecuencias muy negativas para el campo argelino.

La privatización progresiva de las tierras agrícolas socializadas favorece el proceso de concentración, devolución a los antiguos propietarios nacionalizados y asignación de tierras "excedentarias" de la reestructuración a los dignatarios y otros clientes del Estado, han precedido al arrendamiento total o parcial de los lotes de los "nuevos cooperativistas, incapaces o no interesados en cultivar la tierra. Lo que se produjo fue un comienzo de concentración a nivel de explotación que se fue extendiendo a lo que se denomina la vuelta a la propiedad "absentista urbana", que los geógrafos señalan como de dominación del campo por la ciudad, cuestión que se había eliminado gracias a la autogestión y después por la Reforma Agraria.

Para Bouziane Semmoud, un ejemplo de este cambio, en la política agraria, lo tenemos en el desarrollo de la agricultura capitalista en el Sáhara gracias a la A.P.F. (accès a la propriété foncière), cuyo objetivo era poner en cultivo nuevas tierras con vistas a cubrir las necesidades alimentarias crecientes de Argelia. Con la ayuda del Estado que daba agua y tierras gratuitas y compras de material subvencionadas, los nuevos colonos-granjeros, muchos de ellos vinculados al régimen, empresarios y profesionales liberales, originarios de las ciudades del sur o del "gran norte", se entregan a una agricultura depredadora, en donde sólo cuenta el beneficio, destruyendo suelos que son "reliquias", alterando y luego arruinando la economía de los oasis, dejando así en la indigencia a sus habitantes y sobreexplotando los acuíferos, cuya renovación se mantenía equilibrada por la agricultura tradicional. ${ }^{17}$

En el año 2000 se impulsa el Plan Nacional de Desarrollo Agrícola, seguido del Esquema Director Sectorial de Desarrollo Agrícola, con el objetivo de relanzar la economía rural y eliminar las diferencias con el mundo urbano

De nuevo hay un impulso por parte del gobierno para preservar el medio rural, por medio de proyectos que se incluyen en los programas quinquenales de 2004 a 2009 y el de 2010 2014, (Programa Quinquenal 2004-2009 y el de 2010-2014 para la agricultura), con el objetivo de crear 12.000 proyectos de desarrollo agrícola, para progresar hacia una Argelia autosuficiente en alimentación.

En los estudios del profesor Omar Bessaoud, se enfatiza que en Argelia, la estrategia de desarrollo rural sostenido, ha sido elaborada a partir de estudios e inventarios sobre el mundo rural, "sin precedentes" 18 . Se han movilizado todos los recursos posibles para ello, desde el gubernamental, con la Secretaría para el Desarrollo Rural, hasta los organismos internacionales, como la FAO, la PNUD, el Banco Mundial e innumerables centros de investigación, universidades y expertos privados. Los estudios han sido profundos y bien elaborados, pero "se convierten en una investigación intelectual permanente, enfrentada a las experiencias de los actores, que son los campesinos".

\footnotetext{
${ }^{17}$ Semmoud, op. cit.

${ }^{18}$ Bessaoud, op. cit.
} 


\subsection{Composición del hábitat rural según las zonas rurales}

En Argelia, el $45 \%$ de la población rural vive en habitat disperso (cerca de 5.419 .525 habitantes) y un 55\% en habitat concentrado (6.714.401 habitantes) en cerca de 3.500 aglomeraciones rurales o semirurales, que varían según las 48 willayas, o provincias. Estos datos son el resultado de las investigaciones dirigidas por el profesor Bessaoud, quien subraya que no se debe creer que en el hábitat rural haya homogeneidad, pues las diferenciaciones se encuentran tanto en el mundo rural, como entre el rural y el urbano. En los estudios que dirige, se ha podido constatar que la localización geográfica de las comunas rurales se reparte entre las planicies, al norte del país, donde se pueden concentrar hasta un $64 \%$, de comunas rurales y cerca de $11 \%$ de comunas rurales están localizadas en el sur del territorio argelino.

También se hace hincapié, sobre la urbanización creciente en el seno mismo de las zonas rurales e indica que la movilidad de la población es menos desequilibrada, manteniéndose los flujos de población hacia las zonas litorales o hacia ciertos polos urbanos fuertemente atractivos por la industria o el comercio.

Hacia el año 2005 el proceso de urbanización de las poblaciones rurales, creando aglomeraciones rurales o semirurales alrededor de las principales ciudades, se explica gracias a muchos factores que permiten este crecimiento de los recién llegados, como son las mejores condiciones de vida, la realización de infraestructuras y de equipamientos públicos, así como la tendencia al agrupamiento, por razones de seguridad por la "guerra civil" que sufrió el país.

Se indica igualmente que, el éxodo que hoy en día se produce en ciertas wilayas manifiesta el hecho de que el proceso de reabsorción de las desigualdades territoriales y socioeconómicas no puede sostenerse en el tiempo. Movimiento, que en opinión de Bessaoud, contribuirá a marginar una parte del territorio argelino, así como a la sociedad rural, compuesta por agricultores, campesinos y familias, artesanos, etc.

En opinión del profesor argelino Rebouha Fafa, el campesino es el "guardián" del campo, el que lo cuida y cultiva y gracias a él se conserva un bien común que no debería dejarse perder. ${ }^{19}$

Efectivamente, esta opinión es la que debemos tener todos como seres que compartimos la naturaleza y que nos beneficiamos de ella, por los recursos que encierra, y en cuanto a la agricultura, un patrimonio que es indispensable para el sostenimiento de la población.

Hemos visto que las políticas favorables al desarrollo de la agricultura en el medio rural, han resultado insuficientes, o simplemente han fracasado, por no tener en cuenta al actor principal que es el agricultor. Por ello, el Estado argelino no ha dejado de promover proyectos cuyo objetivo sea preservar el medio rural y poder conseguir la autosuficiencia en producción de alimentos.

La iniciativa que se está llevando a cabo en estos años es "la estrategia nacional de desarrollo rural para un horizonte decenal”, de julio de 2005 y el plan de renovación rural de otoño de 2006. Los principios de esta Stratégie de Développement Rural Durable (SDRD), se fundamentan en la intervención directa de las poblaciones rurales y de sus organizaciones, para resolver los problemas a que están abocados, una vez se pongan en marcha los proyectos.

\footnotetext{
${ }^{19}$ Rebouha, Fafa: "Évolution des practiques y projets du monde rural à proximité de métropoles en Algérie. Cas de la région d'Oran", UMR. 6590-ESO, Colloque Faire Campagne, Rennes (2005), en http://eso.cnrs.fr/spip.php?article384.
} 
Los objetivos de la estrategia decenal (2005-2015) han sido definidos y articulados en torno a los siguientes temas:

-Mejora de las condiciones de vida de las poblaciones rurales.

-Empleo y renta para la diversificación de las actividades económicas, agro-silvo-pastorales, artesanales, turismo, servicios, etc.

-Reforzamiento de la cohesión social y territorial.

-Protección del medio ambiente y valoración del patrimonio rural.

Esperamos ver qué resultados habrá tenido esta nueva iniciativa, que cuenta con dos mil proyectos de proximidad de desarrollo rural.

Esta nueva estrategia pone el acento en la seguridad alimentaria, el restablecimiento de los equilibrios ecológicos y la mejora de las condiciones de la vida de las poblaciones rurales.

\section{Túnez}

Túnez es el país más pequeño del Magreb. La superficie que ocupa es de $165.000 \mathrm{~km}$ cuadrados y una población estimada en 10. 300.000 habitantes. Es un país con características propias a partir de su independencia, en 1955, fecha en que pasó a autogobernarse, para después convertirse en una monarquía constitucional, que fue derrocada en el año 1957, y el país se convirtió en una república de corte socialista, con Bourguiba como presidente.

Aproximadamente el $40 \%$ de la superficie del país es desértica, ocupada por el desierto del Sahara, y el resto lo constituye un suelo fértil apto para la agricultura.

Túnez, se ha caracterizado hasta el momento actual por ser el país más occidentalizado de todos los del Magreb, con una clara influencia francesa en sus costumbres y también ser el país más urbanizado de todos los que en este estudio tratamos, con un $62 \%$ de población urbana, repartida en ciudades como Túnez, capital, Bizerta Sousse y Djerba, y Sfax. También es conocido por ser un país culto y el que mayor nivel de instrucción ha tenido respecto a los países vecinos. A partir del derrocamiento de Ben Alí, como consecuencia de la revolución del Jazmín, en 2010-2011, el país está experimentando numerosos cambios que tendrán repercusión en todo el sistema social, político y económico, y que conoceremos a largo plazo.

La zona costera es la más poblada, con una densidad de 100 habitantes por $\mathrm{km} 2$, a diferencia del sur que sólo cuenta con 10 habitantes por km2.

Un dato importante a tener en cuenta, según el Banco Mundial, es su tasa de chabolismo que no supera el $2,1 \%$.

\footnotetext{
${ }^{20}$ Bessaoud, op.cit.
} 


\subsection{Características del sector rural}

La agricultura representa el 16\% del Producto Interior Bruto del país y da empleo a un 22\% de la población activa. Los principales cultivos son los cereales, el aceite de oliva y en el sur del país, los dátiles. Es un país autosuficiente en productos lácteos, verduras y frutas.

El mundo rural tunecino se encuentra enfrentado a numerosos problemas, entre los que se pueden enumerar los siguientes: una población rural muy dispersa, infraestructuras de base insuficientes, ausencia de diversificación de los trabajos, la actividad de producción dominada por la agricultura y una economía agrícola poco comercializada.

Las tierras agrícolas en Túnez ocupan alrededor de 10.000.000 de has., repartidas entre la superficie agrícola útil, que representa el 50\%, unos 5.000.000 de has.; los bosques, con un $7 \%$ de superficie, vías unos 4,3 millones de has, o un $43 \%$ de superficie, y los cultivos de huerta, que ocupan un $53 \%$ de la SAU.

Para los expertos en este tema que nos ocupa, el caso de Túnez es el resultado del subdesarrollo rural acumulado a lo largo de los años de independencia. A pesar de los planes de desarrollo agrícola y rural, promovidos por el gobierno, no se han visto unos resultados satisfactorios, en cuanto a la reducción de los desniveles de desarrollo sectorial e interregional en materia de mejora de las condiciones de vida campesina, empleo y salarios, lo que hace pensar que el sector rural sigue arrastrando problemas como, una productividad global endeble, un salario menor que el de otros sectores, un subempleo estructural y una oferta de empleo muy limitada, y una infraestructura económica y social poco desarrollada.

En cuanto a la estructura agraria se refiere, ésta se caracteriza por estar constituida por granjas de pequeño tamaño y sin mecanizar. El 80\% de las explotaciones agrarias cuenta con menos de 20 has, y sólo el $3 \%$ tiene más de 50 has.

Como consecuencia de una severa sequía del año 2000, el gobierno tunecino puso en marcha del Plan Nacional Agrícola del año 2001, que tuvo como objetivo potenciar la agricultura y promover un mejor bienestar para la población rural.

Como consecuencia de un desarrollo rural frágil y de la evolución económica del medio urbano, en Túnez se ha podido constatar la existencia de dos tipos de flujos migratorios, uno interior y otro exterior.

\subsection{Migración interior}

La migración interna se produce desde el campo a las ciudades de la zona costera y hacia la capital. También hay movimientos de población hacia villas rurales.

Como en Marruecos y Argelia, el motivo principal que induce a los campesinos a dejar el campo es la mejora del salario, que es superior en las zonas urbanas. Para los estudiosos de las ciencias sociales, esta decisión no es muy clara, porque creen que "si en realidad, sopesaran el costo de la vida en la ciudad, esta motivación se convertiría en ilusoria", ya que la ciudad, implica gastos de todo tipo, que no se reducen simplemente a la alimentación. Pero sea como fuere, la motivación económica es la principal causa de atracción que ejerce la ciudad, sobre los campesinos, especialmente si son jóvenes.

La diferencia entre salarios rurales y urbanos es evidente que sea un factor importante, pero no determinante, porque también influyen otros factores como la posibilidad de 
promoción social según el trabajo en que se empleen, el modo de vida urbano, los servicios con que cuentan las ciudades, sanitarios, escolares, culturales, de ocio y turísticos, como ocurre con ciudades como Túnez, Hammamet y Sousse.

En cifras, la emigración interior durante el período 1980-1984, supuso un desplazamiento de 274.900 personas, que sufrió un descenso para el período 1984-1989, con un saldo de 137.100 personas. $^{21}$

Tanto los movimientos migratorios internos como externos han engendrado ciertos desequilibrios a nivel de la economía tunecina, que se traducen en la escasez de mano de obra en sectores sensibles como es el de la agricultura, así como un envejecimiento de la población rural activa.

Por desgracia, el paro y el subempleo es lo que lleva a los jóvenes a emigrar, aunque algunos especialistas en estudios sobre empleo, indican que no sólo estos factores hacen que la gente emigre, sino también la aparición de nuevas necesidades, que diferencian al medio urbano del rural, así como la necesidad de buscar otros beneficios que los emigrantes consideran más importantes. $^{22}$

Túnez es un país que ha tenido un movimiento de población interna desde siempre, pero a partir del año 1966 fue constante y creciente, de tal forma que en el período de 1956-1966, en número de migrantes del campo a los centros urbanos fue de 52.000 personas al año, para el período 1966-1971, experimentar una subida de 77.000 personas por año. En el censo de 1975, el movimiento de población interior está motivado por la necesidad de mano de obra en las minas, concretamente en Gafsa. Región que se ha caracterizado por las "convulsiones sociales" debido a la dureza del trabajo en las minas de fosfatos, controladas por la Compagnie des Phosphates de Gafsa, que fue apoyada por el régimen del derrocado Ben Alí.

De todas formas, Túnez, capital, es la zona que más atracción ejerce sobre el conjunto del país, y es conocido que en el período 1999-2004, el Gran Túnez recibió el 35\% de toda la migración interior del país. ${ }^{23}$

\subsection{Transformaciones en el espacio rural}

La actividad agrícola sigue siendo la principal ocupación en el medio rural. Desde 1984 a 2003, la población rural tuvo un peso respecto a la población total de Túnez, que varío de un 47,2\%, al 39\% y en 2003, representaba aún el 36\% del total nacional. En el año 2010, había disminuido considerablemente, representando sólo un $21 \% .{ }^{24}$ En términos de empleo, el $36 \%$ de la población total residía en el medio rural en 2003, pero sólo el $50 \%$ de estos activos se ocupaba en los sectores de la agricultura.

Consideran los expertos que en Túnez, la actividad agrícola ha perdido importancia en el medio rural y a nivel nacional, como consecuencia del medio rural. Pues el empleo en el sector agrícola no representa más que el $21 \%$ del empleo total del país, y la contribución de la

\footnotetext{
21 "Enquête population et emploi" (1989); Véase: Mzali, Hassen: "Marché du travail, migrations internes et internationals en Tunisie", Revue Région et Développement, $\mathrm{n}^{\circ} 6$ (1997), en http://region-developpement.univtln.fr/en/pdf/R6/Mzali.pdf.

${ }^{22}$ Ibid.

23 "Enquête population et employ", INS (2004).

24 "The State of Food and agriculture", FAO (2012), pp. 114 a 120.
} 
agricultura no representaba más que un 10 a 12\% del PIB. En cuanto a las exportaciones, no representa más que el $10 \%$.

Según datos del Banco Mundial para 2010, el sector agrícola sigue siendo importante en este país, con una contribución al PIB de alrededor del 10\%, empleando al $16 \%$ de la población activa total y $27 \%$ de la mano de obra rural. El crecimiento del sector, sin embargo, va en descenso respecto al crecimiento general, con una media anual del 2,8\%.

A pesar de los proyectos de desarrollo que se han ido programando y llevando a cabo a lo largo de la vida independiente del país, estos han tenido pobres resultados, en general, pues no han conseguido que la pobreza rural disminuya ni tampoco han podido fijar a la población en el medio rural.

Desde la independencia, con el Programa de Desarrollo Rural Integrado de Primera Generación, de 1956 a 1982, se manifestó claramente que el gobierno tunecino estaba dispuesto a cortar con el pasado, por medio de la socialización de los medios de producción, que desarrollo, aunque de forma limitada, a favor de las regiones menos desarrolladas. Se intentó un desarrollo de la productividad y la mejora de los medios de vida de las poblaciones rurales, pero la mayoría de los campesinos no se beneficiaron del régimen de cooperativas. La mayoría sólo entró a trabajar como mano de obra sub-empleada en zonas marginales y para trabajos de conservación de aguas, de suelos, etc. El número de personas que llegó a enrolarse en las obras promovidas por el gobierno al final de los años sesenta, fue de 48.716 personas, que representaban sólo el 4,5\% de la población activa a nivel nacional. Durante los años 1970, la política de desarrollo dejó muy poco lugar para el desarrollo rural. Solamente, con el Programa de desarrollo regional y animación rural (PDR), se vienen a corregir las distorsiones inducidas por el modelo de desarrollo anterior.

Esta política de desarrollo no ayudó a disminuir los desequilibrios existentes ni a detener el éxodo rural, que tomaba proporciones inquietantes, favorecido por las condiciones interiores del medio rural, y por el desarrollo de la industria, que favorecía el empleo en el medio urbano y mejores condiciones de vida.

En Túnez, los desequilibrios regionales existentes entre el campo y la ciudad, no sólo son fruto de una herencia histórica, sino también de las políticas llevadas a cabo para el desarrollo rural y agrario, después de la independencia, es la opinión del profesor Mohamed Elloumi. $^{25}$

Vistos los errores cometidos en cuanto a desarrollo del medio rural y agrícola, en el año 1983 se lleva a cabo con la ayuda y asesoramiento de la FAO, un programa de desarrollo rural integrado, que permitió la intervención en un número considerable de zonas, creando una cierta dinámica que favoreciera una política de precios favorable a los productos agrícolas. Asegura, Mohamed Elloumi ${ }^{26}$, que el PDRI fue la principal forma de intervención en el mundo rural tunecino, durante el período 1984 a 1994. Los proyectos en número de 190, cubrieron cada una de las zonas estudiadas, permitiendo el desarrollo de diferentes actividades, con el objetivo de promocionar la agricultura.

Indica, igualmente que a mediados de los años noventa, Túnez se adhiere al GATT, a la OMC, en abril de 1994, a la zona de libre cambio (ZLE) con la UE, en enero de 1996, con lo

\footnotetext{
25 Elloumi, Mohamed: "Les politiques de développement rural en Tunisie: Acquis et perspectives. Options Mediterranéennes", Serie A, nº 71 (2006), en http://ressources.ciheam.org/om/pdf/a71/06400057.pdf.

${ }^{26}$ Ibid., p. 58.
} 
que Túnez entraba de lleno en el período de liberalización y de apertura a los mercados. Esta apertura, a pesar de la "protección" gubernamental, se esperaba con interés por parte de los agentes económicos rurales, como incentivo al mercado de los productos agrícolas hacia el exterior y también para un intercambio interior más favorable al sector rural y a los campesinos. Esto es lo que llaman algunos expertos, el post-ajuste y el desarrollo participativo. Como resultado más significativo se señala "el cambio profundo de los modos de intervención del Estado, con una fuerte descentralización" y mayor participación de los actores locales, así como la promoción de las ONG en el desarrollo. En el medio rural, en el mes de mayo de 1999, se crea por parte del gobierno del Groupements de Développement Agricole (GDA), que incentivan las estructuras de participación de la población, en cada uno de los proyectos a ejecutar, para favorecer el desarrollo de su territorio y de la región. En cuanto a los efectos negativos de la liberalización, se indica que estos se comprobaron en los cambios inducidos en el tejido económico al asegurar la gestión de los recursos naturales a los agentes del mercado.

El último de los programas que se lanzó, antes del derrocamiento de Ben Alí, se tituló Programa de Desarrollo Rural Integrado de Segunda Generación. (1994-2004), donde se acentúan los proyectos que se habían puesto en práctica desde 1999. También se pone el énfasis en la protección del medio natural, por medio de la valoración de estrategias de conservación medioambiental, la movilización de recursos para conservación de los acuíferos, los recursos forestales y pastoriles. También se tiene en cuenta la "lucha contra la desertización", por medio de obras de gran envergadura que protejan los oasis, con infraestructuras de carreteras, en el sur del país, y la fijación de las dunas.

Con todas las iniciativas gubernamentales lo más destacado es que, en el caso de Túnez, las condiciones de vida del medio rural han mejorado, pues las tasas de pobreza en el medio rural respecto al urbano han caído en mayor proporción, así en 1990 en el medio rural teníamos una tasa de 5,7 por mil, mientras que en el año 2000, fue de 2,9 por mil. En el medio urbano, en el año 1990 se registraba una tasa de pobreza de 6.7 por mil habitantes, y en el año 2000, se había reducido a sólo $4,2 .^{27}$

El último proyecto del que tenemos referencia está subvencionado por el Banco Mundial $^{28}$ y destinado al desarrollo rural y del medio ambiente en Túnez. El 21 de diciembre de 2010 fue aprobado este proyecto para el desarrollo de las zonas de montaña y de bosques del Noroeste de Túnez, con un montante de 41,6 millones de dólares. Se especifica en los objetivos, que "Túnez ha hecho grandes esfuerzos para reducir la pobreza", pero todavía quedan zonas que requieren nuevos esfuerzos.

El proyecto se enmarca dentro de las directivas del gobierno establecidas dentro del 12 Plan de Développement Économique et Social (2010-2014), cuyos objetivos son: mejorar las condiciones socioeconómicas de la población rural y promover una mejor protección y gestión durable de los recursos naturales en las zonas del proyecto a través de la puesta en marcha de la participación integrada del desarrollo comunal

\footnotetext{
${ }^{27}$ INS (2000), en Elloumi, op.cit. p.62.

${ }^{28}$ Tunisie/ Développement rural et de l'environnement/ Un Nouveau projet soutenu par la Banque modiale dans le secteur du développement rural et de l'environnement (APO) (21 diciembre 2010), en http://appablog.wordpress.com/2010/12/21/tunisie-developpement-rural-et-de-1\%E2\%80\%99environnement-unnouveau-projet-soutenu-par-la-banque-mondiale-dans-le-secteur-du-developpement-rural-et-de$1 \% \mathrm{E} 2 \% 80 \% 99$ environnement/.
} 
Esperamos que la realización de este proyecto se esté llevando a cabo y no se haya postergado por parte de las autoridades que hoy gobiernan Túnez.

\section{Conclusión}

Como podemos deducir, la situación de los tres países estudiados se asemeja, al participar todos ellos de una considerable extensión del desierto del Sahara y encontrarse en una región de escasa pluviometría.

Se han realizado muchos "ensayos" en el medio rural, de los que se ha fracasado en una parte no pequeña, aunque han servido para "tomar nota" de lo que no se tiene que hacer.

Hay que subrayar que el elemento principal del campo no es sólo la agricultura sino el campesino y su familia. Por ello, es muy importante que los gobiernos de estos países tengan en cuenta su opinión, como actores que trabajan la tierra y saben de qué hablan. De igual forma hay que tener en cuenta a los expertos, en materia agrícola, a los investigadores y tomar nota de la situación de dependencia que estos países tienen respecto al clima. Esto les hace vulnerables en cuanto a seguridad alimenticia se refiere, porque el progresivo crecimiento de la población urbana, demandará cada vez más alimentos y estos sólo se producen en el medio rural.

Los tres países están realizando grandes esfuerzos para mejorar la situación del medio rural y de sus habitantes, sin embargo, las migraciones son casi permanentes, del campo a la ciudad, de la ciudad al extranjero y, en medio se encuentra la migración en tránsito procedente de diversos países del continente africano.

Hasta el día de hoy, y según hemos podido comprobar, los planes de desarrollo agrícola y para el medio rural no han dado como resultado, el evitar o por lo menos disminuir las migraciones del campo a la ciudad. Los flujos continúan y no se nota que los alicientes que se han creado para mejorar la situación rural en cada uno de los países aquí estudiados, haya procurado una disminución o un freno a los flujos migratorios campo-ciudad. Incluso ha habido especialistas de las migraciones que llegan a afirmar que, los hábitat rurales, una vez sus poblaciones han experimentado alguno de los beneficios que les permitan vivir de una forma más confortable, como pueda ser la comunicación por carretera, la electrificación, la comodidad de tener agua corriente, entre otras, sin embargo, todo ello contribuye a que gran parte de la población rural emprenda el éxodo hacia las zonas urbanas. Todo en función del prestigio que tienen las ocupaciones y empleos en la ciudad, respecto al desprestigio que se ha creado en relación a las ocupaciones rurales. Podemos decir, que el espejismo de la ciudad arrastra a los jóvenes campesinos, más que a los mayores. Con ello el campo sufre por la falta de mano de obra y por el envejecimiento de su población.

Hemos visto como este continuo desplazamiento del campo a la ciudad está creando distorsiones en los distintos países, con desequilibrios regionales patentes, como el caso de Túnez, con un litoral prácticamente colapsado por las ciudades, y el resto del país prácticamente vacío.

Mientras la situación del campesino no mejore y se vean las ocupaciones del campo con el prestigio que se ven las de las zonas urbanas, las poblaciones, en especial las más jóvenes, seguirán emigrando del campo a la ciudad. 
¿Qué oportunidades se les ha dado a los campesinos para proponer ideas de actuación, que les beneficiaran y les ayudaran a mantenerse en el campo, como un valor imprescindible y conocedor de las necesidades y de los beneficios de la tierra, ante las reformas emprendidas por sus gobiernos? En nuestra opinión, muy pocas, teniendo en cuenta que en la ribera norte del Mediterráneo, estas actuaciones de una política neoliberal, en beneficio del capital y de la ciudad, ya se han producido, con no menos perjuicio para las poblaciones campesinas, que también se vieron en la necesidad de emigrar del campo a la ciudad y alimentar a las masas depauperadas de los suburbios urbanos, enseñanza que no vemos que se haya tenido en cuenta en estos países, por parte de los mandatarios.

Tiene toda la apariencia de una repetición de lo que se ha hecho en países de la UE. El campesino pierde su medio de vida y ve cómo sus tierras se convierten en cultivos intensivos para la exportación, pasando a emigrar de forma que van a engrosar la pobreza urbana, mientras sus tierras o pasan a manos de otros campesinos con más medios, o a manos de especuladores, y también a las de los constructores para convertirlas en viviendas urbanas. 